\title{
Mass Customization in Supply Chain Level: Development of a Conceptual Framework to Manage and Assess Performance
}

\author{
Mahnoosh Zebardast, Silvia Malpezi, and Marco Taisch \\ Politecnico di Milano, Department of Management, Economics and Industrial Engineering, \\ Via Lambruschini 4/b 20156, Milano, Italy \\ \{mahnoosh.zebardast and silvia.malpezi\}@mail.polimi.it, \\ marco.taischapolimi.it
}

\begin{abstract}
Recent market interest on customized offers and intensive competition on attracting market globally, lead companies to implement supply chain management to improve performance and gain competitive advantage. To this aim, Supply chain management in customer-oriented environment is pursuing the transition from traditional supply chain into concurrent flexible and efficient one. This paper aims to understand specifically how supply chain within this environment needs to be configured and managed in order to enable efficient customization for mass market. To reach this goal, a conceptual framework and list of indicators to support the framework have been developed and tested.
\end{abstract}

Keywords: Mass customization, Supply chain management, Performance measurement.

\section{Introduction and Research Objectives}

There is a growing recognition among scholars and practitioners that individual businesses no longer compete as stand-alone entities, but rather as supply chains [3]. Recently, we are now entering the area of "network competition," where the awards will go to those organizations who can better structure, coordinate, and manage the relationships with partners in a network which is committed for a better, closer, and more agile relationships with final customers [3]. It can be argued that in today's challenging global markets, the route to sustainable advantage lies in being able to leverage the respective strengths and competencies of network partners to achieve greater responsiveness to market needs [3]. Evidently market interest on more customized offers better aligned to individual's needs, brings further challenges in terms of complexity and uncertainty. Being competitive in this environment requires concurrent efficiency and flexibility [8]; accordingly enables the ability to provide higher variety at lower cost, enabling strategies of mass customization to be pursued [3]. Mass customization is defined differently by many scholars time after time [5], [27], [29], [41] but the most well-known definition used by this study, is given by Piller as "Customer co-design process of products and services, which meet the needs of each individual 
customer with regard to certain product features. All operations are performed within a fixed solution space, characterized by stable but still flexible and responsive processes"[28].

Inspired by extensive literature review, we recognized that the literature on mass customization in supply chain level has been growing recently and there are still some areas that need further research. In particular we believe that more understanding is needed on how to configure and manage a supply chain in such environment. Therefore, the purpose of this paper is to analyze the configuration and management of supply chain while implementing mass customization. More specifically, the research objectives of this paper are (1) understanding factors necessary to be considered in order to configure and manage the supply chain while implementing mass customization; and (2) recognizing how these factors can be measured. To reach these goals, we first did the literature review and tried to cluster it into research areas to construct our understandings. Four research areas relevant to our objectives were identified. Afterwards relevant factors and indicators related to each research areas were identified and structured in a consistent and understandable framework. In this framework, factors were structured from literature while indicators were developed by this study. As last step we tried to validate the framework by three case studies that employed mass customization at the time of data collection in diverse industries. We shaped this paper as follows: first, we delivered a literature review, next we explained the methodology employed. Then, we presented the framework and finally, we explained validation phase and made the conclusion.

\section{$2 \quad$ Literature Review}

With the aim of mass customization, customer needs to be involved into value creation processes. This involvement can happen in different stages, in relation to different actors within supply chain The degree of customer involvement in literature is known as customization level and has been discussed extremely by scholars [6], [18], [30], $[36,37]$. Moreover, the capability of supply chain in implementing it is known as postponement. Graman defines postponement as the capability of supply chain in delaying the activities associated to differentiation of product_customization processes_closer to the time that demand is known [8]. Literature positions postponement differently. Some recognize it only in manufacturing operations [2], [11], [32, 33] while some others take a broad view and distinguish it in supply chain level specially emphasize on differentiation in distribution point [39]. Within those who consider postponement in supply chain level, many discuss about issues such as the conflict between product variety and quick response time [16], or product growth and cost control at certain point $[32,33]$. Generally literature discusses about postponement by either focusing on types of postponement (time, form and place), their evaluation and comparison [11], [17], [39, 40]; or targeting management of inventory to set optimal level of inventory [2], [8], [24], [32, 33]. In both of these groups modularization has been recognized as an enabling method for efficient customization. Based on our literature review, this study analyses modularization to the aim of a better understanding about this method by focusing on its characteristics and advantages [4], [19], [35], [44]. It specifically 
discusses about the need for a more intimate relationship among supply chain partners to produce, supply and manage the inventory of modules for customization [13], [20], $[22,23]$. Literature has put more attention on relationships among partners in customer oriented environments where a more flexible and efficient supply chain is requested. The relationship is interpreted as integration and cooperation between suppliermanufacturer, manufacturer-customer; and among internal divisions of manufacturer [15], [22], [25], [34], [45, 46]. Literature rarely differentiates cooperation and integration and draws the line between them. Some studies, like Pan and Holland [4], defines cooperation as a beneficial relationship between actors namely customer, manufacturer and other partners such as supplier and distributers. It is believed that this relationship aims to improve outcomes like customer satisfaction, time to market or resource usage by setting common objectives and reducing duplicated activities for increasing value added activities [46]. Integration is a more rigorous concept which aims to integrate the actors in both ends (downstream and upstream) to achieve an optimal output. It includes integration of processes, activities, locations and etc. to optimize the performance of all actors as a whole [15], [20, 21]. Moreover, it decreases uncertainties and increases flexibility and responsiveness [20,21].

\section{$3 \quad$ Methodology}

In the first step of this research "supply chain" and "mass customization" were searched in keywords and abstract sections without any restriction or preference over journals. In total 71 articles from 39 different journals were selected to be reviewed. Papers were analyzed in a more detailed level and their main focuses in supply chain were recognized and subsequently clustered (e.g. postponement, modularity and etc.). The output of this step was twelve clusters covering different strategies and methods, called research areas. These research areas have been the starting point for the construction of our framework. Since the conceptual framework was based on literature, this study validated it empirically by three case studies in different industries. Unit of analysis was manufacturer supply chain (only including first layer suppliers), research domain was manufacturing industry/sector implementing mass customization at the time of data collection, regardless of the size or the level of customization; and expected respondents were operation manager and owner. Validation phase was done by online questionnaire. In particular, the questionnaire consisted of four parts representing framework subjects and aimed to test associated factors and indicators. Questions were multiple choice (without restriction on number of choices) and openend. Multiple choice questions were used for validation of factors and indicators while open-end questions aimed to initiate respondents to add missing impacting factors and/or indicators.

\section{Conceptual Framework}

A conceptual framework was developed to support configuration and management of supply chain. It identifies four main decision areas that are about relationship 
management, postponement, level of customization, and modularity level. To reach our objectives, by conceptual framework, we tried to understand relevant elements to be considered for each decision area. For instance in order to manage relationship along a supply chain, this study expects that an industry needs to consider elements such as customer integration level and supplier selection criteria. By following, we structure the work in four sections associated to the framework decision areas. In each section, first we briefly define the decision area and associated elements. Afterwards, we specify relevant impacting factors and indicators for each element (see Table 1).

\subsection{Relationship Management}

The first decision area is related to different relations that a company (manufacturer) should have with players in supply chain. The aim is to primarily understand who is considered as key partner and is necessary to build close relationship; and how to manage these different kinds of relationships while practicing mass customization. To reach this goal, four types of elements are necessary to be considered. These elements are briefly defined by following:

Internal integration level: This element refers to relations inside the manufacturer and points out the importance of internal capabilities in satisfying customer needs responsively. In particular, this element brings out level of interaction between internal departments and employees.

Customer integration level: This element highlights the importance of customer and their value-adding contribution inside the supply chain processes. Specifically this element deals with the extension of customer contribution and management of the transferred knowledge.

Cooperation level with partners: This element focuses on how to define the extent of relation and then how to manage it with different actors such as suppliers and distributors.

Partners' selection criteria: This element emphasizes on the basics which needs to be considered in order to select some partners over the others.

\subsection{Customization Level}

The second area relates to the marginal value that customization brings to the end customer. Definition of this value impacts on the way supply chain operates and creates the customization marginal value. Mass customization levels can be driven from tailored customization (customization in fabrication), customized standardization (customization in assembly); and segmented standardization (customization in package and distribution) [18]. In order to identify the customization level, a company needs to consider three elements. These elements are briefly defined by following: 
Product characteristics: This element refers to product features that support decisions related to customization.

Partners' characteristics: This element refers to capabilities, characteristics and relationships of actors inside the supply chain.

Market characteristics: This element refers to extent of customization in relation to market need.

\subsection{Modularity Level}

Third decision area is related to a method known as modularization that enables a company to efficiently customize products. This study considers only the set of elements, related to the production process and supply chain characteristics, that impacts on product modularization, hence excluding elements related to other types of modularization (such as organizational modularity). The impacting elements are briefly defined by following:

Product characteristics: This element refers to product features that support decisions related to customization.

Partners' characteristics: This element refers to capabilities of actors inside the supply chain which operationally support modularization.

Production system characteristics: This element refers to production capabilities inside of the manufacturing which operationally support modularization.

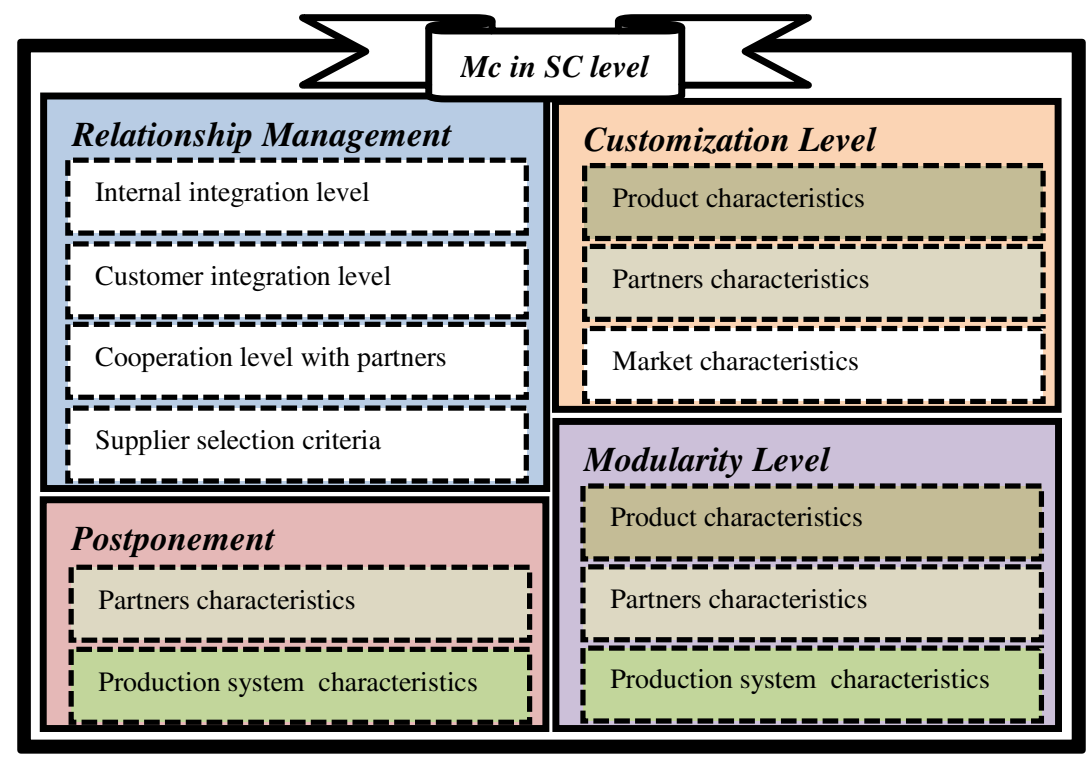

Fig. 1. Conceptual Framework 


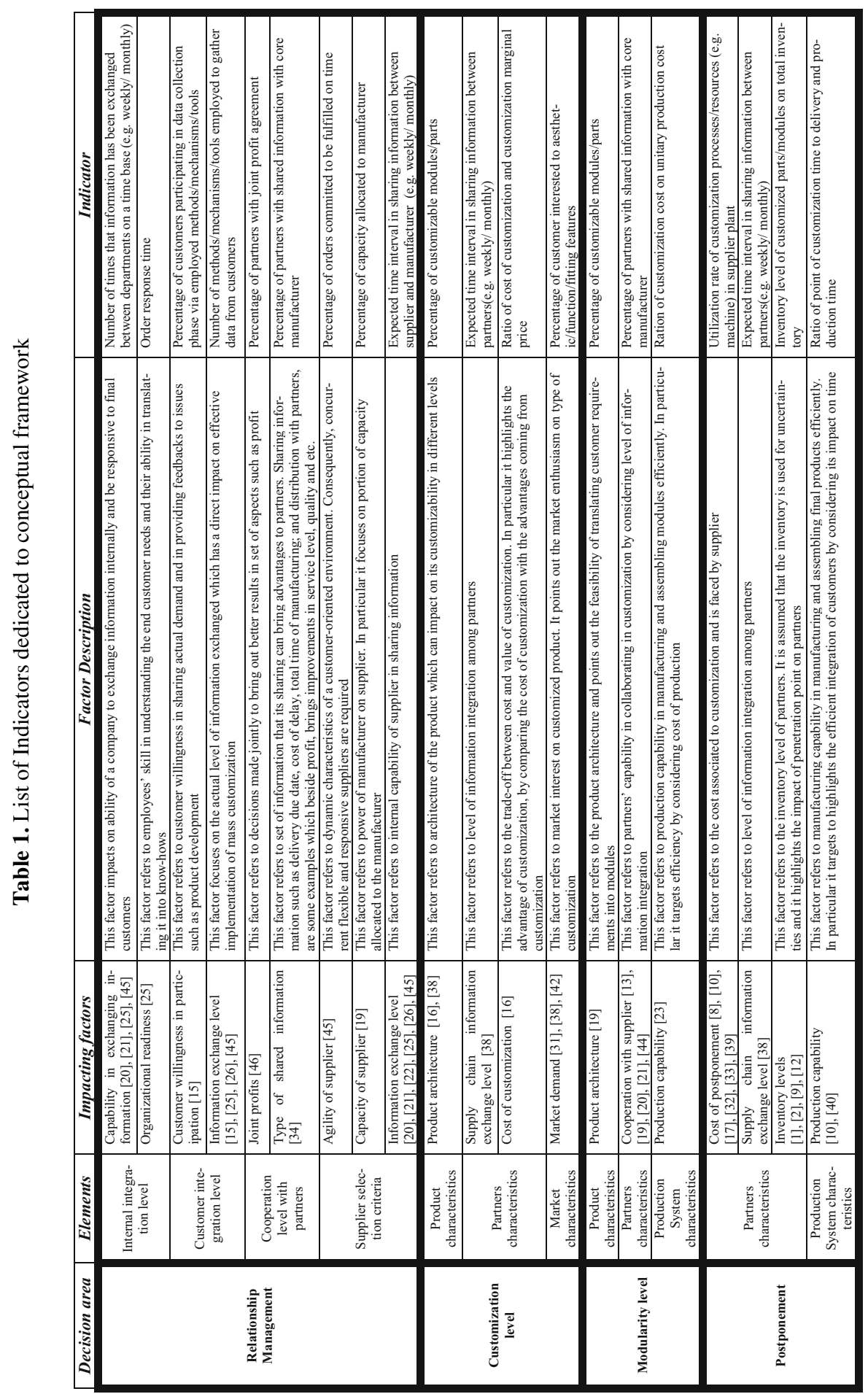




\subsection{Postponement}

Last subject is related to the postponement strategy known as capability of a supply chain to perform customization in a way to delay differentiation or customization closer to the time that demand for the product is known [8]. The aim of this group is to understand appropriate position of customer integration point. To reach this goal, we identify two elements necessary to be considered. These elements are briefly defined by following:

Partners' characteristics: This element refers to partners' capability in either carrying out the customization in their location (e.g. distributors' ability in customizing products) or being collaborative and responsive to support core company postponement strategy.

Production system characteristics: This element refers to production capabilities inside of the manufacturing which operationally support customer intervention.

\section{$5 \quad$ Validation and Conclusion}

As a final step this study conducted three case studies to validate its findings. In particular by case studies, we tried to understand if impacting factors are practically considered in configuration and management of supply chain. Moreover we tried to test indicators relevance by asking if they are already applied in practice or can be considered beneficial. Based on our case studies, all impacting factors were validated but certain indicators were not. Customer willingness in participation was never measured and its measurement was believed challenging. Moreover, although all three cases had modular product, but believed that proposed indicator for product architecture was not representative; instead they assert that ration of customizable modules cost on production cost was suggested to be substitute. As a result of this study we create a better understanding of how different factors impact on configuration and management of supply chain in customer-oriented environment. Moreover, we suggest a list of indicators that can support decisions with a better indication on circumstances.

Acknowledgements. This work was partly done by Merve Murathanoglu as her master thesis in Politecnico di Milano University. Moreover, this paper has been partly funded by the European Commission through S-MC-S (Sustainable Mass Customization - Mass Customization for Sustainability) Project (Grant Agreement No: FoF.NMP.2010-2 260090 - S-MC-S) and project called "New business models for manufacturing and services".

\section{References}

1. Aigbedo, H.: An assessment of the effect of Mass Customization on suppliers' inventory levels in a JIT supply chain. European Journal of Operational Research 181, 704-715 (2007) 
2. Baozhuang, N., Shouping, G., Zhiyong, Z., Xinghua, L.: An optimal inventory model based on postponement strategy: a bilevel programming approach. International Journal of Mass Customization 2, 341-357 (2008)

3. Christopher, M.: The Agile Supply Chain: Competing in Volatile Markets. Industrial Marketing Management 29(1), 37-44 (2000)

4. da Cunha, C., Agard, B., Kusiak, A.: Design for Cost: Module-Based Mass Customization. Automation Science and Engineering 4(3), 350-359 (2007)

5. Davis, S.: Future Perfect. Addison-Wesley, Massachusetts (1987)

6. Gilmore, J., Pine, J.: The four forces of mass customization. Harvard Business Review (1997)

7. Glavic, P., Lukman, R.: Review of sustainability terms and their definitions. Cleaner Production (2007)

8. Graman, G.A.: A partial-postponement decision cost model. European Journal of Operational Research 201(1), 34-44 (2010)

9. Guohua, C., Jihong, P.: Study on Behavior Characteristics of Supply Chain for Mass Customization. In: International Conference on Intelligent Computation Technology and Automation (ICICTA), vol. 3, pp. 474-477 (2010)

10. Hoek, R.V.: Postponed manufacturing: a case study in the food supply chain. Supply Chain Management: An International Journal 2(2), 63-75 (1997)

11. Hoek, R.V.: Postponement and the reconfiguration challenge for food supply chains. Supply Chain Management: An International Journal 4(1), 18-34 (1999)

12. Hoek, R.V.: Role of third party logistic services in customization through postponement. International Journal of Service Industry Management 11(4), 374-387 (2000)

13. Howard, M., Squire, B.: Modularization and the impact on supply relationships. International Journal of Operations \& Production Management 27(11), 1192-1212 (2007)

14. Huang, G.Q., Zhang, X., Lo, V.H.Y.: Optimal supply chain configuration for platform products: impacts of commonality, demand variability and quantity discount. International Journal of Mass Customisation 1(1), 1742-4208 (2005)

15. Jitpaiboon, T., Dangols, R., Walters, J.: The study of cooperative relationships and mass customization. Management Research News 32(9), 804-815 (2009)

16. Ji, X.H., Sun, D.Y.: Evaluation of delayed product differentiation structures forcoordinating product, process and supply chain design. In: IEEE 18Th International Conference on Industrial Engineering and Engineering Management (IE\&EM), vol. 3, pp. 1458-1462 (2011)

17. Kisperska-Moron, D., Swierczek, A.: The selected determinants of manufacturing postponement within supply chain context: An international study. International Journal of Production Economics 133(1), 192-200 (2011)

18. Lampel, J., Mintzberg, H.: Customizing customization. Sloan Management Review (1996)

19. Lau, A.K.W.: Critical success factors in managing modular production design: Six company case studies in Hong Kong, China, and Singapore. Journal of Engineering and Technology Management 28(3), 168-183 (2011)

20. Lau, A.K.W., Yam, R.C.M., Tang, E.P.Y.: Supply chain integration and product modularity An empirical study of product performance for selected Hong Kong manufacturing industries. International Journal of Operations \& Production Management 30(1), 20-56 (2010)

21. Lau, A.K.W., Yam, R.C.M., Tang, E.P.Y., Sun, H.Y.: Factors influencing the relationship between product modularity and supply chain integration. International Journal of Operations \& Production Management 30(9), 951-977 (2010) 
22. Liao, K., Ma, Z., Lee, J.Y., Ke, K.: Achieving mass customization through trust-driven information sharing: a supplier's perspective. Management Research Review 34(5), 541-552 (2011)

23. Lin, Y., Zhou, L., Shi, Y., Ma, S.: 3C framework for modular supply networks in the Chinese automotive industry. International Journal of Logistics Management 20(3), 322-341 (2009)

24. Ma, S., Wang, W., Liu, L.: Commonality and postponement in multistage assembly systems. European Journal of Operational Research 142(3), 523-538 (2002)

25. Moser, K., Piller, F.T.: Integration challenges of mass customization businesses: the case of Steppenwolf. International Journal of Mass Customisation 1(4), 507-522 (2006)

26. Pan, B., Holland, R.: A mass customized supply chain for the fashion system at the designproduction interface. Journal of Fashion Marketing and Management 10(3), 345-359 (2006)

27. Piller, F.T., Reichwald, R., Tseng, M.M.: Competitive advantage through customer centric enterprises. International Journal Mass Customization 1(2/3), 157-165 (2006)

28. Piller, F.T.: Mass customization: reflection on the state of the concept. International Journal of Flexible Manufacturing System 16(4), 313-334 (2004)

29. Pine, B.-J.: Mass customization: The new frontier in business competition. Harvard University Press (1993)

30. Pine, B.J., Victor, B., Boynton, A.C.: Making mass customizatin work. Harvard Business Review (1993)

31. Poulin, M., Montreuil, B., Martel, A.: Implications of personalization offers on demand and supply network design: A case from the golf club industry. European Journal of Operational Research 169(3), 996-1009 (2006)

32. Qin, Y.: On capacity allocation model of partial postponement strategy. Procedia Engineering 15, 4342-4346 (2011)

33. Qin, Y.: Optimal partial postponement capacity of the single-period product under stochastic demand. Procedia Engineering 15, 4347-4351 (2011)

34. Qin, Y.: A stackelberg-game model in a two-stage supply chain. Systems Engineering Procedia 3, 268-274 (2012)

35. Ro, Y., Liker, J.K., Fixson, S.K.: Modularity as a Strategy for Supply Chain Coordination: The Case of U.S. Auto. IEEE Transactions on Date of Publication Engineering Management 54(1), 172-189 (2007)

36. Silveira, G.D., Borenstein, D., Fogliatto, F.S.: Mass customization: Litreture review and research directions. International Journal Producion Economics 4(6), 842-848 (2000)

37. Spira, J.: Mass customization through training at Lutron Electronics. Computers in Industry (1996)

38. Stavrulaki, E., Davis, M.: Aligning products with supply chain processes and strategy. International Journal of Logistics Management 21(1), 127-151 (2010)

39. Su, J.C.P., Chang, Y., Ferguson, M.: Evaluation of postponement structures to accommodate mass customization. Journal of Operations Management 23(3-4), 305-318 (2005)

40. Trentin, A., Forza, C.: Design for form postponement: do not overlook organization design. International Journal of Operations \& Production Management 30(4), 338-364 (2010)

41. Tseng, M.M., Jiao, J.: Mass Customization. Gaviel Salvendy, pp. 684-709. Wiley, New York (2001)

42. Yimer, A.D., Demirli, K.: A genetic approach to two-phase optimization of dynamic supply chain scheduling. Computers \& Industrial Engineering 58(3), 411-422 (2010) 
43. Yu, W., Jie, L.: Supply Chain Model Based on Multi-CODP in Mass Dynamic Customization. In: International Conference onInformation Management, Innovation Management and Industrial Engineering, ICIII 2008, vol. 2, pp. 252-255 (2008)

44. Wang, Z.: Study on supply chain management for product family in mass customization. In: IEEE International Conference on Automation and Logistics, pp. 1515-1519 (2007)

45. Wang, J., Fan, Y., Li, X.: The Strategy of Harmonize and Optimize Their Supply Chain Management under Mass Customization. In: 2007 IEEE International Conference on $\mathrm{Au}-$ tomation and Logistics, pp. 2550-2554 (2007)

46. Zhanga, X., Huangb, G.Q.: Game-theoretic approach to simultaneous configuration of platform products and supply chains with one manufacturing firm and multiple cooperative suppliers. International Journal of Production Economics 124(1), 121-136 (2010) 